\title{
High In Situ Stress Anisotropy Lead to Formation of Complex Fracture Patterns
}

\author{
Xinjiang Yan $\mathbb{D}^{1},{ }^{1}$ Zehao Zhang, ${ }^{1}$ Jifei Yu, ${ }^{1}$ Yanfeng Cao, ${ }^{1}$ and Yanguang Yuan ${ }^{2}$ \\ ${ }^{1}$ CNOOC Research Institute, Beijing, China \\ ${ }^{2}$ BitCan Geosciences \& Engineering Inc., Calgary, AB, Canada
}

Correspondence should be addressed to Xinjiang Yan; yanxj3@cnooc.com.cn

Received 19 August 2020; Revised 25 November 2020; Accepted 6 January 2021; Published 27 January 2021

Academic Editor: Xiaorong Li

Copyright (C) 2021 Xinjiang Yan et al. This is an open access article distributed under the Creative Commons Attribution License, which permits unrestricted use, distribution, and reproduction in any medium, provided the original work is properly cited.

\begin{abstract}
During the process of water injection, due to solid particle deposition and foreign liquid intrusion, the formation near the wellbore was contaminated and blocked. As a result, water injection rate reduced and failed to meet the injection requirements. In order to improve water injection rate and improve oil recovery of offshore oilfields, hydraulic injection tests were carried out in controlled laboratory conditions. In general, the formation of complex fracture patterns is an ideal outcome of the hydraulic fracturing stimulation seeks to achieve. In situ stress condition is an inherited geological condition one can only adopt to. By comparing test results of different experiments that had varied stress and hydraulic injection conditions imposed, we can investigate their impact on the fracture patterns created. This paper presents laboratory evidences to support that if the hydraulic injection condition is managed properly, a complex fracture pattern is possible even under a high in situ stress anisotropy. Even if the in situ stress condition has a large anisotropy, proper hydraulic stimulation operations can still cause complex fracture patterns and thus provide good stimulation efficiency.
\end{abstract}

\section{Introduction}

In offshore oilfield, many mature injection wells are faced with challenges of being severely blocked and thus face difficulties reaching allocated injection rate targets. Acidizing stimulation is usually used to clear up the near-wellbore blockage and increase well injection rate. Unfortunately, the benefit is temporary and risk of frequent acidizing increases rapidly as the acidizing stimulation continues. This increases cost and causes collateral contamination, seriously impeding reservoir production and project return on investment. Therefore, it is urgent to find out a well stimulation method that can increase well injection rate at low cost, causing no contamination and having a long effective duration.

Hydraulic dilation uses controlled high-pressure injection to alter the microstructures of a rock material, forming a zone of increased porosity and localized microtensile cracks. Using theoretical analysis and simulation on field data, Yuan et al. $[1,2]$ concluded that in unconsolidated sandstone formations, the sand grains are first sheared over each other by the high-pressure injection so that their compaction state changes from the previously densely compacted state to a loosely compacted state. Afterwards, when the injection pressure continues to increase, these disturbed sand grains can separate from each other, causing tensile cracks or open shear cracks. Based on laboratory test results and field test data, Yuan [3] showed that these microtensile cracks are often arranged into echelon arrays. They do not connect with each other to form a continuous fracture path, but are dispersed separately in the otherwise continuous rock medium. It is postulated that these cracks must be connected by a tortuous path in the $3 \mathrm{D}$ space. Therefore, hydraulic dilation is different from hydraulic fracturing stimulation. In the latter, a continuous tensile fracture is often created.

The hydraulic dilation stimulation has been successfully applied in the oil sand field, benefiting well injection and ultimately benefiting well production. Yuan et al. [4] and Yuan [3] presented field injection/production data, demonstrating that the dilation can increase well injection rate and meanwhile create uniform conformance of the injected materials 


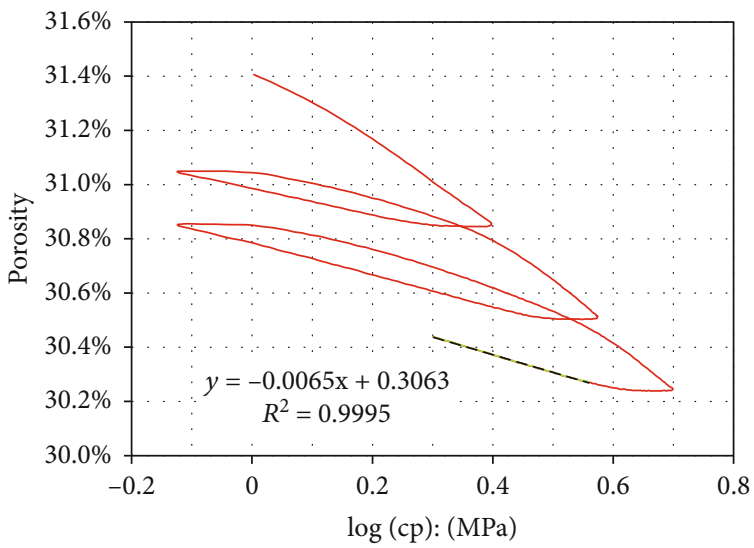

(a)

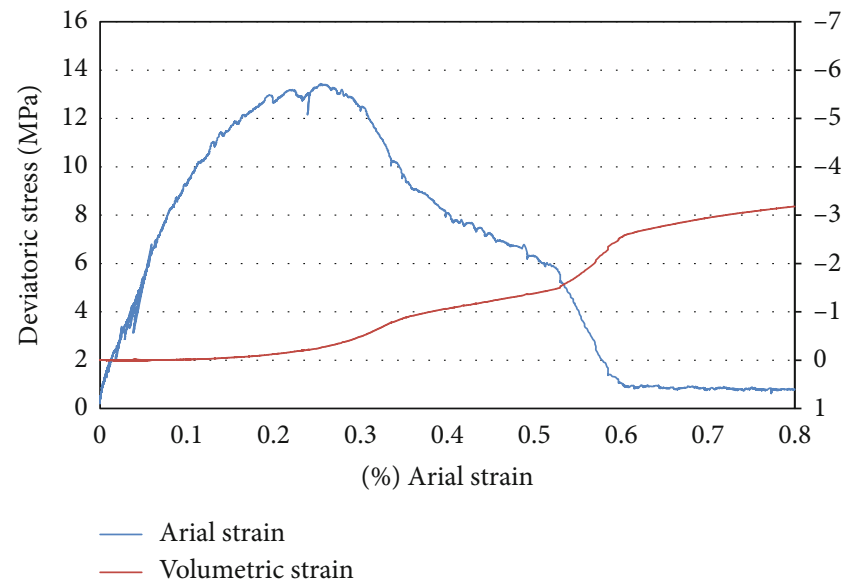

(b)

FIgUre 1: Triaxial test curve on sample A3 at a confining pressure of $2 \mathrm{MPa}$.

along the injection interval. As a result, both well production and stimulation efficiency increase. Similar supportive field data can be found in [5-10] and [11].

Specifically, the injection rate and conformance improvement by hydraulic dilation cannot be realized by hydraulic fracturing. As described previously, the fracturing tends to increase injection rate only, but compromises the uniform conformance. A negative impact on long-term well production was illustrated in Yuan [3] by field data if the well is hydraulically fractured.

Therefore, hydraulic dilation offers an alternative to stimulate reservoirs other than the hydraulic fracturing, opening up more possibility for innovation. Objectives of the laboratory test program were to investigate if hydraulic dilation can be used to increase well injection rate for water injection is normally used to maintain sufficient driving pressure for producing from brown fields.

A series of controlled laboratory tests were completed to investigate fracture patterns under various injection rates and schedules. It was carried out in a traditional triaxial cell. A hole was drilled at the center of each test sample halfway into its height from one end, simulating an injected well. A special-purpose injection port in the loading platen was connected to the hole to simulate well injection. It was found that different fracture patterns were formed under a variety of injection conditions and stress conditions. Primarily, a smaller difference between the prescribed principal stresses could form discrete fracture paths, while a larger difference (but with properly managed hydraulic injection conditions) caused a complex fracture geometry (i.e., numerous microcracks were observed in the samples). This is contrary to the traditional thought about impact of in situ stress anisotropy on fracture complexities. This and other observations are shared in this paper and discussions are given relating to the causal mechanisms.

The following description will provide some background information about the target field application and its associated reservoir condition. It then describes the laboratory test settings, including sample preparation and test conditions. A summary is presented about different fracture patterns observed. Finally, a discussion is given about the underlying mechanisms, their relevance to the current knowledge on fracture complexities, and how the laboratory test will guide the field operations for oil/gas production.

\section{Basic Characteristics of Target Reservoirs}

The reservoir rocks tested were of Paleogene geological age. Test samples came from depths of approximately $2600 \mathrm{~m}$. In laboratory measurements, its porosities ranged from 
TABLE 1: Comparison of representative elastoplastic parameters between the Athabasca oil sands and the current target reservoir sands.

\begin{tabular}{lcccc}
\hline \multicolumn{1}{c}{ Sample } & & $\begin{array}{c}\text { Cp' } \\
\text { MPa }\end{array}$ & $\begin{array}{c}\text { Linear Young's } \\
\text { moduls, GPa }\end{array}$ & $\begin{array}{c}\text { Dilation } \\
\text { angle, }\end{array}$ \\
\hline \multirow{4}{*}{$\begin{array}{l}\text { Current target } \\
\text { reservoir sands }\end{array}$} & A2 & 0.1 & 3.176 & 55 \\
& A3 & 2.0 & 7.448 & 57 \\
& A4 & 5.0 & 17.140 & 58 \\
\hline \multirow{3}{*}{ Athabasca oil sand } & 1 & 0.05 & 0.077 & 53 \\
in Alberta, Canada & 2 & 0.1 & 0.079 & 52 \\
& 4 & 0.3 & 0.186 & 48 \\
& 5 & 0.6 & 0.206 & 44 \\
& 6 & 0.7 & 0.226 & 41 \\
& & & 0.233 & 34 \\
\hline
\end{tabular}

$20.7 \%$ to $28.7 \%$ with an average of $24.2 \%$. Permeability varied from 165.2 to $7674.1 \mathrm{mD}$ with an average of $1806.7 \mathrm{mD}$. Overall, the reservoir was normally pressured, of normal thermal gradients, and belonged to a medium-porosity and high-permeability type. Its in situ stress regime was similar to the normal fault type.

Triaxial tests were performed to benchmark the target reservoir rocks. Figure 1 shows a compaction test curve, a stress-strain curve, and a volumetric strain-axial strain curve, respectively, under a condition of confining pressure of $2 \mathrm{MPa}$ and room temperature $\left(25^{\circ} \mathrm{C}\right)$.

Linear elastic Young's modulus and dilation angles for different confining pressures were compared between the target reservoir sand in the current study and the Athabasca oil sands in Alberta, Canada. As we can see from the result in Table 1, our target reservoir has a stiff elastic response while its dilation tendency was strong, which is similar to that of Athabascan's. The hydraulic dilation stimulation technology has been successfully applied in the Athabasca oil sands to increase well injection rate and improve well conformance.

A similar dilation tendency between the current target reservoir and the Athabasca oil sands and success observed in the latter encouraged the current laboratory test program.

\section{Laboratory Test Details}

3.1. Sample Preparation. Because of its weakly consolidated nature, cores obtained from the field were limited in quantity and quality and did not meet needs of the tests. As an alternative, artificially made samples are used for the following hydraulic injection tests. The samples were created from silica sands and cement in different proportions according to an ASTM standard [12]. The sand was specially graded to retain $98 \%$ on a No. $100(150 \mu)$ sieve, $75 \%$ on a No. 50 $(300 \mu), 30 \%$ on a No. $40(425 \mu)$, and $2 \%$ on a No. 30 $(600 \mu)$. Specific gravity was 2.65 . The exact quartz/cement portion was determined by the following steps: (1) preparing different artificial samples by mixing different silica/cement ratios; (2) testing their unconfined compressive strength (UCS) of the corresponding samples (Figure 2); and (3)

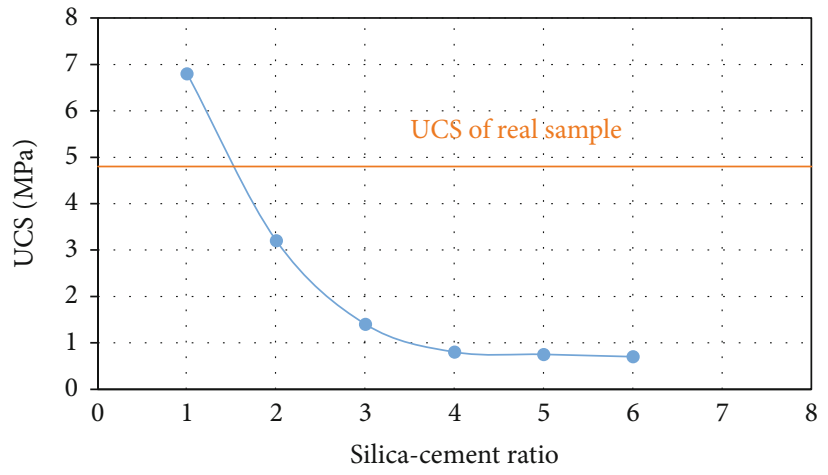

FIGURE 2: Effect of different silica/cement ratios on the UCS properties of corresponding artificial samples.

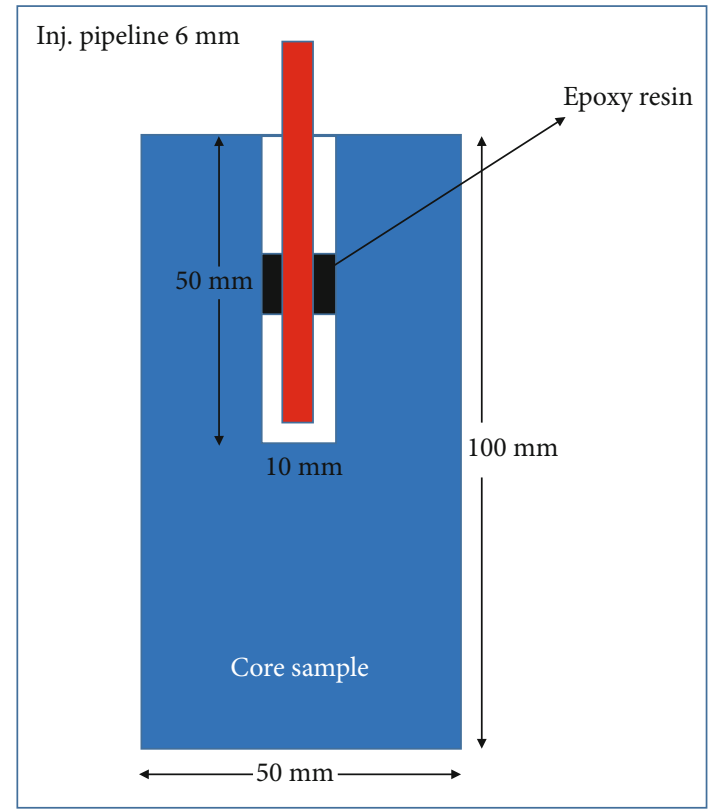

FIGURE 3: A schematic showing the test sample configuration.

selecting the silica/cement ratio that yielded a UCS value similar to that measured on the actual core samples (denoted on Figure 3). This test yielded the optimal silica/cement ratio of 1.6 .

The sample was made into a diameter of $50 \mathrm{~mm}$ and height of $100 \mathrm{~mm}$. A hole of $10 \mathrm{~mm}$ in diameter and $50 \mathrm{~mm}$ in height was drilled from the sample top. This simulated the injection well in the field. A schematic is shown in Figure 3.

3.2. Equipment Setup. The sample was placed in the conventional triaxial cylinder where it was subject to a prescribed confining pressure and axial stress condition. By using a special loading platen, a special made hydraulic injection line was connected with and inserted into the mimic injection well. A piece of high-strength epoxy was placed at approximately half the height of the injection well so that the lower section of the well was exposed to the high-pressure injection. Major test indices of the experiments were to investigate the impact of different injection conditions on the fracture 


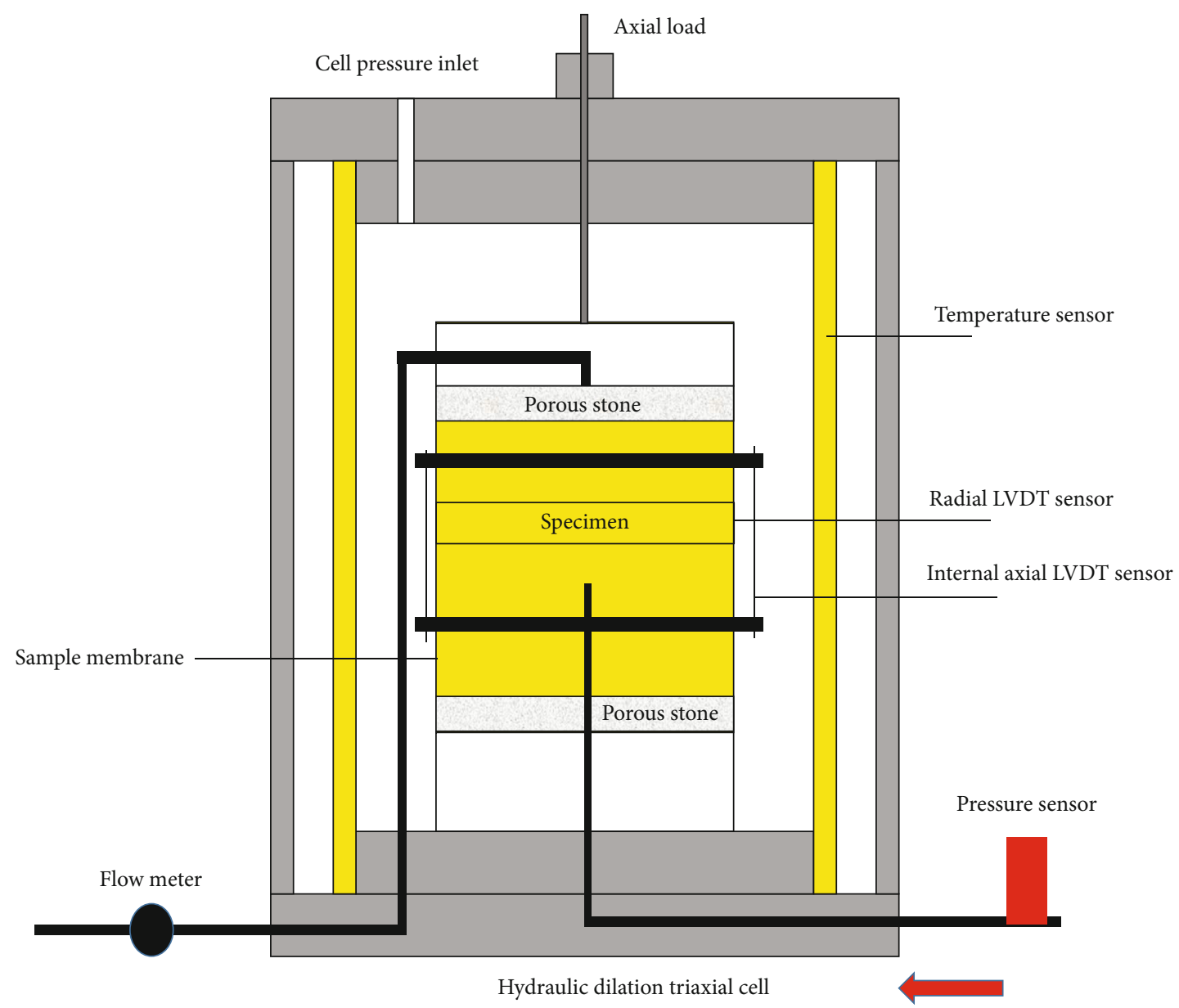

Figure 4: Hydraulic dilation txiaxial cell.

patterns formed in the sample. The tested samples were first visually examined and then CT-scanned to examine the fracture patterns inside. Crack density was calculated from the CT images using an image processing software. Test equipment are shown in Figure 4.

\section{Representative Laboratory Test Results}

The tests have demonstrated that under proper management of injection pressure and rate conditions, we have different hydraulic stimulation outcomes. Either relatively simple discrete tensile fractures or complex microcrack dominated fracture patterns can be created. An example of discrete tensile fractures is given in Figure 5 and a complex microcrack fracture pattern is shown in Figure 6. Their corresponding injection pressure/rate conditions are shown in Figure 7.

Sample B9 in Figure 5 was subject to a larger confining pressure $(18 \mathrm{MPa})$ and a deviatoric stress $(10 \mathrm{MPa})$, which is equal to $56 \%$ of the confining pressure. Injection into this sample was at a constant rate of $2.5 \mathrm{cc} / \mathrm{min}$ (as shown in Figure 7). Sample B7 in Figure 6 had a confining pressure of $5 \mathrm{MPa}$ and a deviatoric stress of $5 \mathrm{MPa}$, which is equal to the confining pressure. Its injection started with a conditioning phase lasting 17 hours at a constant injection pressure of $4 \mathrm{MPa}$ (Figure 7). Then, a large injection rate averaged at approximately $5 \mathrm{cc} / \mathrm{min}$ was applied to raise the injection pressure and cause the sample to fail. Fractures developed in samples B9 and B7 yielded a crack density of 1.7 and $5.5 \% \mathrm{~m}^{2} / \mathrm{m}^{3}$, respectively. As expected, the complex fractured sample B7 had a higher crack density, which is three times more than that of the relative simply fractured sample B9.

Fractures developed in samples B9 and B7 yielded a crack density of 1.7 and $5.5 \% \mathrm{~m}^{2} / \mathrm{m}^{3}$, respectively. As expected, the complex fractured sample B7 had a higher crack density, which is three times more than that of the relative simply fractured sample B9.

Figure 8 further compares the fracture pattern created in two tests, which were carried out at a nearly identical injection rate $(2.0$ to $2.5 \mathrm{cc} / \mathrm{min})$, identical confining pressure $(5 \mathrm{MPa})$, but two different deviatoric stress conditions. Sample $\mathrm{A}$ to the left in Figure 8 had deviatoric stress $=2$ $\mathrm{MPa}$ (i.e., $40 \%$ of the confining pressure). Fractures formed in this sample were of the relatively simple discrete type. Sample B to the right had deviatoric stress $=5 \mathrm{MPa}$, which is $100 \%$ of the confining pressure. Fractures formed in sample B were much more complex with numerous microcracks formed inside.

The injection pressure response during the tests for the previously described samples $\mathrm{A}$ and $\mathrm{B}$ are shown in Figure 9. At a constant injection rate of $2.0 \mathrm{cc} / \mathrm{min}$, tests on 


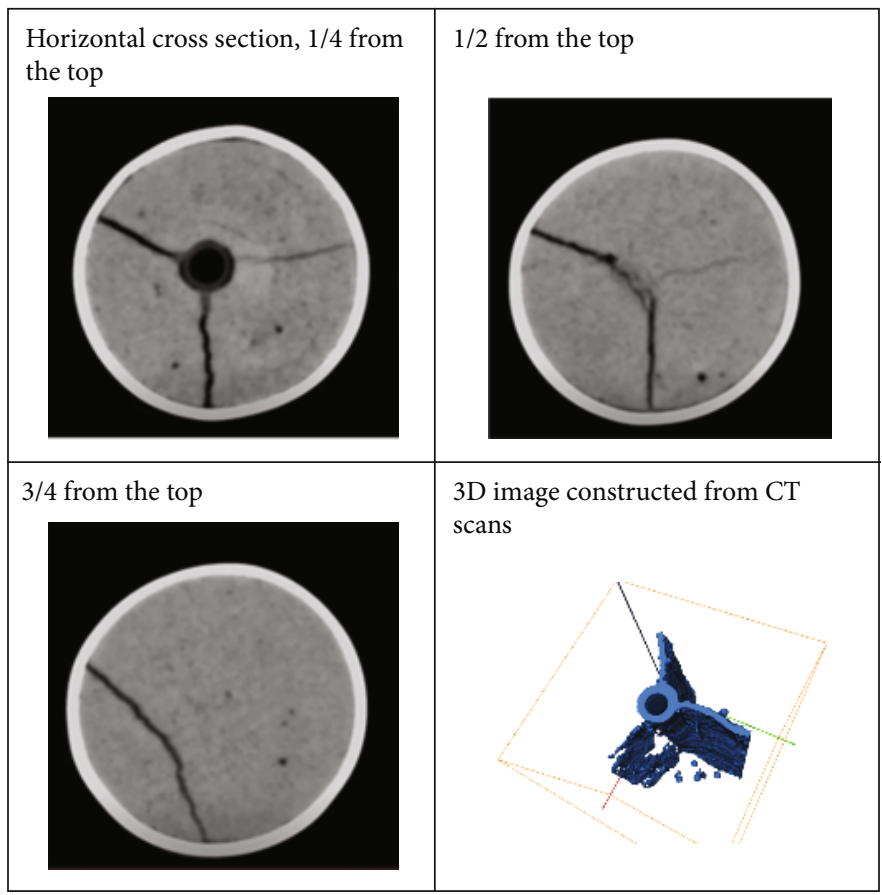

FIgURE 5: CT scan images showing discrete tensile fractures. Sample B9.

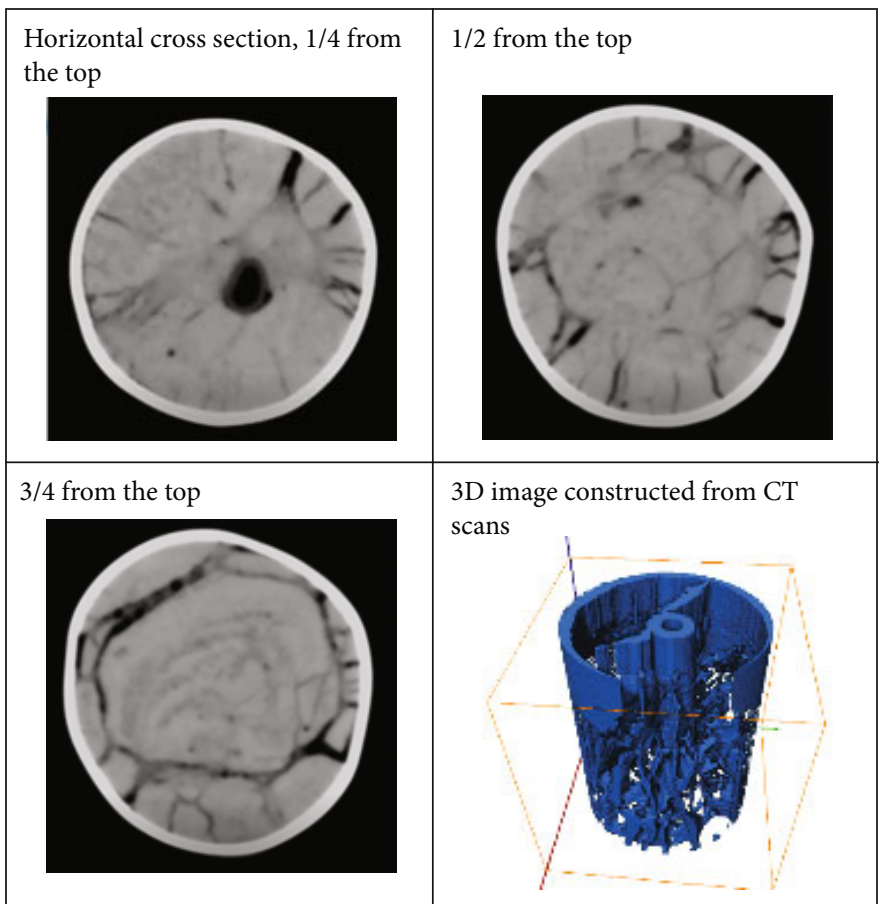

FIgURE 6: CT scan images showing a complex fracture pattern. Sample B7.

sample A had a continuous increase in the injection pressure until the pressure reached the peak. Then, the injection pressure dropped. This is similar to the breakdown event commonly observed in hydraulic fracturing, which signals formation of fractures and thus a sudden increase in the injection rate. Sample B had two stepped rise periods in the injection pressure. The pressure remained relatively constant at approximately 1 and $6 \mathrm{MPa}$ for 2 to 3 minutes. Thus, the entire injection period was longer in sample B than in sample A. This means that the injection pressure had more time to diffuse into the sample, similar to the pressure-conditioning phase used in sample B7 (as shown in Figure 7).

As a final illustration on use of the hydraulic injection tests to investigate the stimulated effect, a cyclic pressure test 


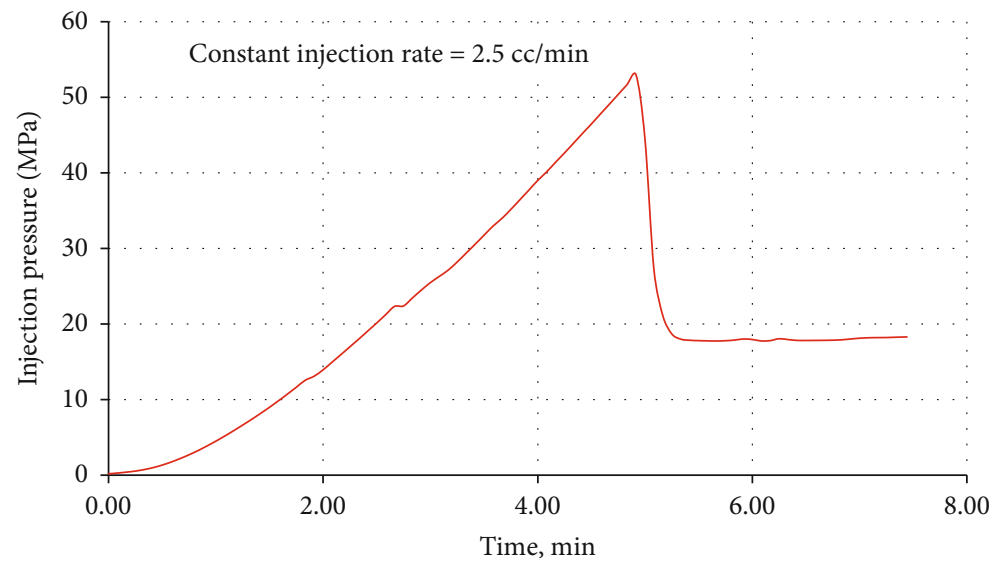

(a)

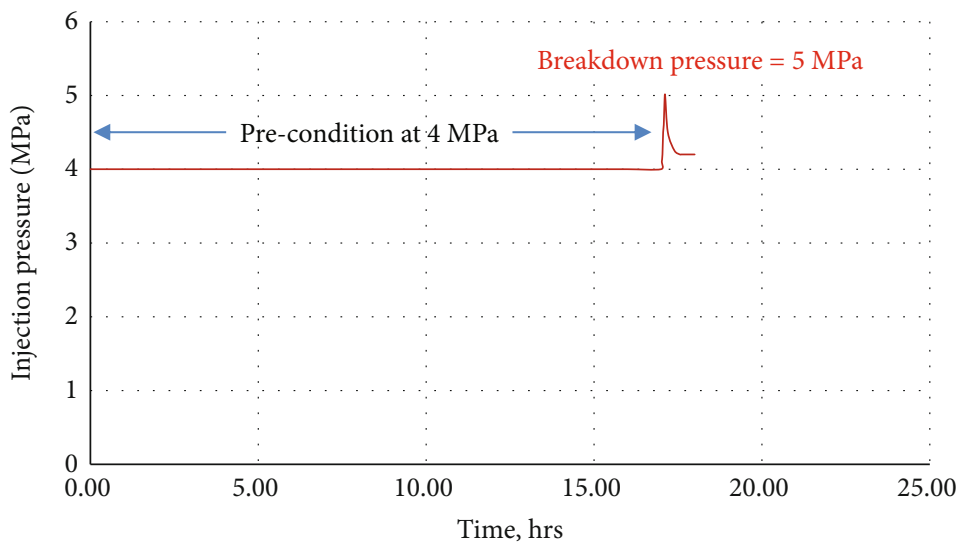

(b)

Figure 7: Injection pressure response in samples B9 (a) and B7 (b) during the hydraulic injection tests.

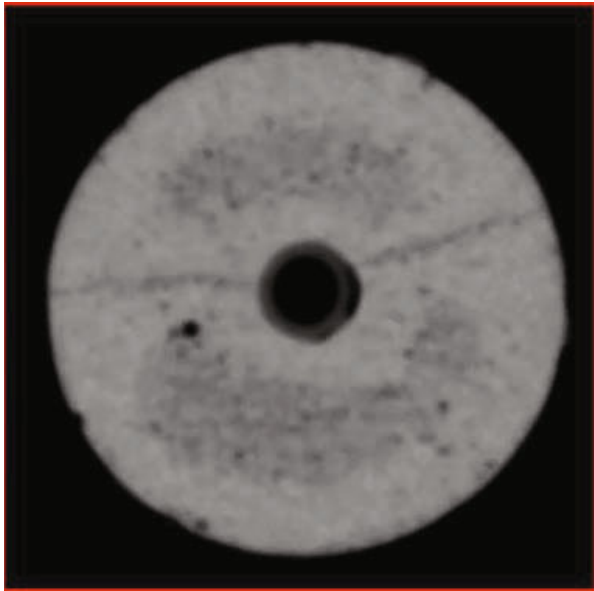

(a)

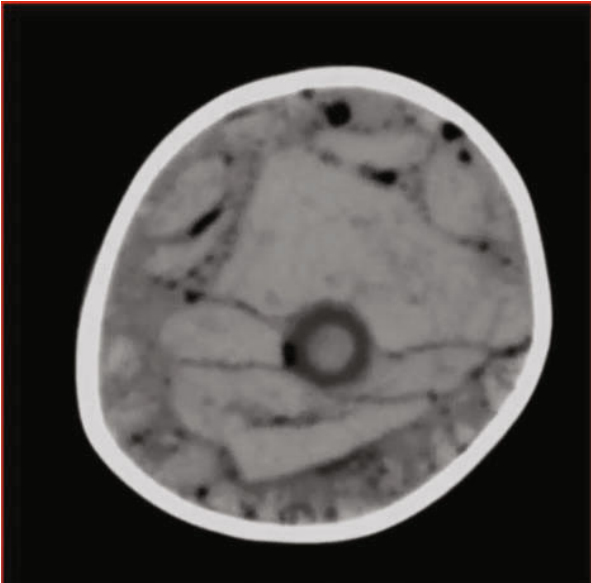

(b)

FIgURE 8: Crack patterns seen from CT scans along horizontal cross sections on samples A and B.

is described next. It was intended to study if the pressure cycles can also cause complex fracture patterns. The sample was subject to a confining pressure of $5 \mathrm{MPa}$ and a deviatoric stress of $3 \mathrm{MPa}$. The cyclic pressure loading is shown in the top of Figure 10 (i.e., its frequency was $1 / 5 \mathrm{~min}$ ). After the pressure cycles were finished, the injection condition changed to a constant rate at $5 \mathrm{cc} / \mathrm{min}$ until the sample failed. The injection pressure response is also shown in the middle of Figure 10. Thus, it did not register an obvious breakdown event. The CT scans of the tested sample in the bottom of 


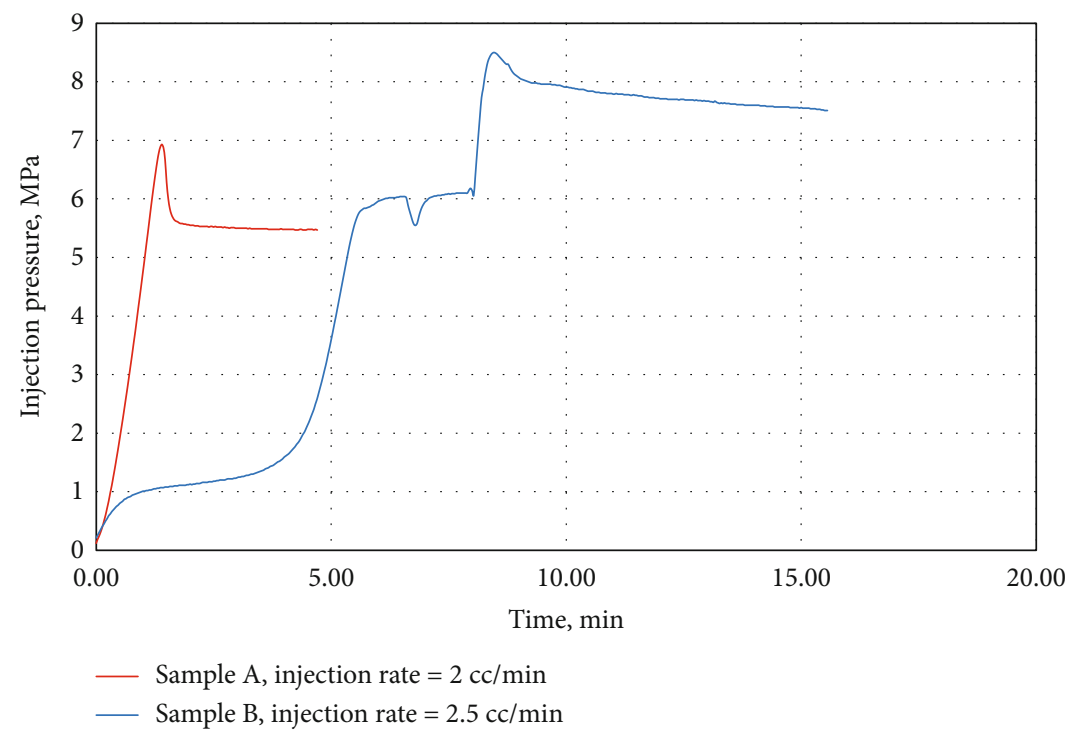

Figure 9: Injection pressure response for samples A and B shown in Figure 8.

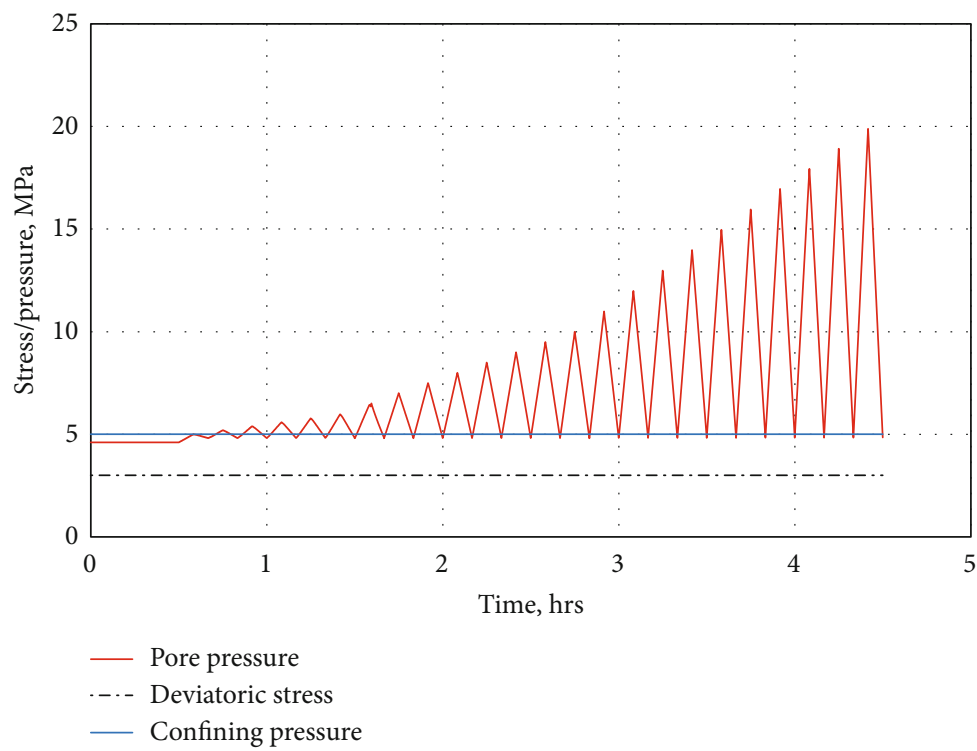

(a)

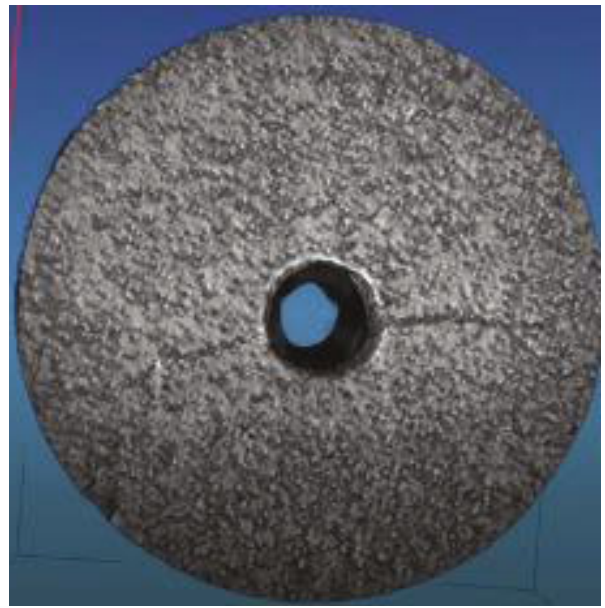

(b)

Figure 10: (a) Cyclic pressure loading, confining pressure, and deviatoric stress conditions applied; (b) CT scans of the tested sample.

Figure 10 show two isolated discrete tensile fractures only (i.e., no complex fracture pattern was formed).

Both discrete fracture patterns and microcrackdominated fracture patterns were observed in the tests. Certain hydraulic injection strategies can be used to favor occurrences of the microcrack patterns. To discover these effective injection strategies and aid the discussion, the initial stress condition is plotted in Figure 11 for the different test samples, of which the results are presented above. Relevant details on the initial stress condition, injection condition, and observed crack patterns are also summarized in Table 2. The DruckerPrager strength line in Figure 11 was measured on the real reservoir rocks of the present study.

\section{Discussions and Conclusion}

This paper presents a hydraulic injection test program under controlled laboratory test conditions. Different stress conditions and injection conditions were added to investigate their impact on fracture patterns formed in the sample. It was aimed to seek an effective water injection strategy in improved or enhanced oil recovery to increase water injection rate and, meanwhile, to improve well conformance. For this purpose, hydraulic fracture stimulation should be avoided because it commonly forms discrete tensile fractures. A tensile fracture can increase the well injection rate but is detrimental to the well conformance. An alternative is to use geomechanical 


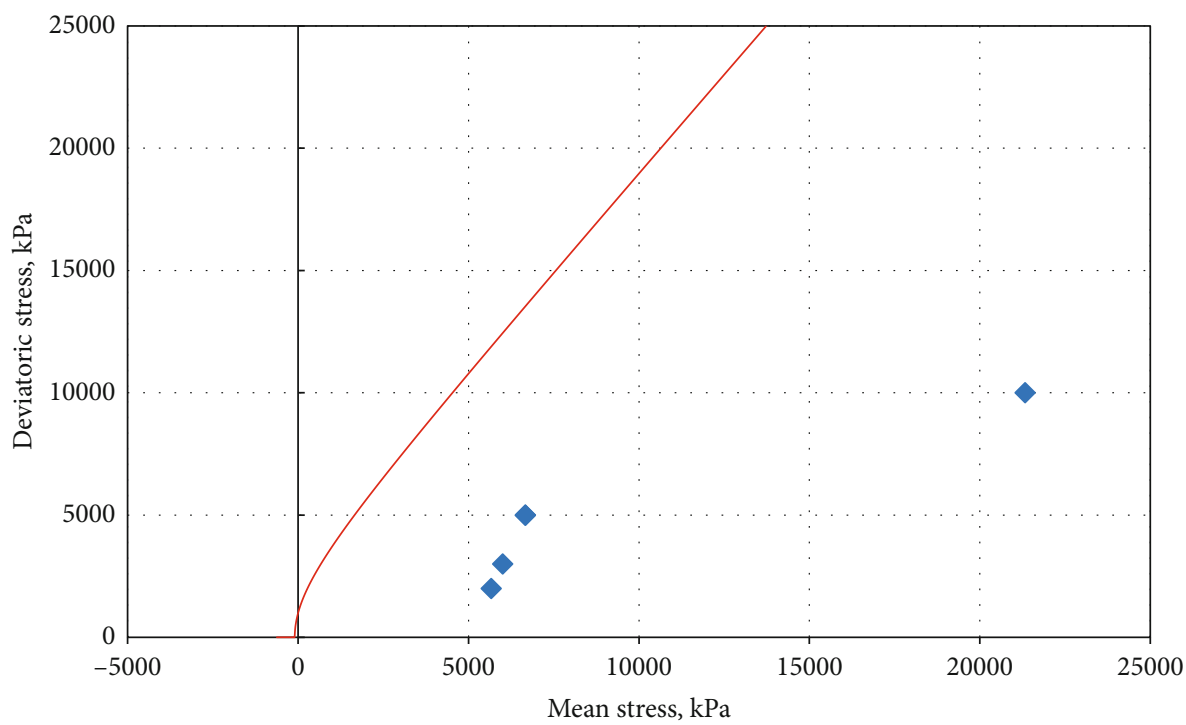

Figure 11: Initial stress condition of different test samples with respect to a material strength line plotted on Drucker-Prager (i.e., deviatoric stress vs. mean stress) diagram.

TABLE 2: Summary of relevant test conditions and results.

\begin{tabular}{|c|c|c|c|c|c|}
\hline \multirow{2}{*}{ Sample } & \multicolumn{2}{|c|}{ Stress condition, $\mathrm{kPa}$} & \multirow{2}{*}{ Fracture pattern } & \multicolumn{2}{|c|}{ Injection condition } \\
\hline & Mean stress & Deviatoric stress & & Rate,cc/min & Condition add \\
\hline B9 & 21333 & 10000 & Discreate & 2.5 & No \\
\hline B7 & 6667 & 5000 & Micro-crack & 5 & $17 \mathrm{hrs}$ at $4 \mathrm{MPa}$ \\
\hline A in Figure 8 & 5667 & 2000 & Discreate & 2 & No \\
\hline $\mathrm{B}$ in Figure 8 & 6667 & 5000 & Micro-crack & 2.5 & A total of 3 mins at 1 and $6 \mathrm{Mpa}$ \\
\hline
\end{tabular}

dilation mechanisms to form complex fracture patterns which involve shear movement of sand grains and natural factures and formation of discrete microcracks.

During some of the hydraulic injection tests, complexities occurred in the servo control of the triaxial test system. As the injection pressure increased, it became close or larger than the confining pressure. This happened when the sample was approaching failure or after failure. At this time, the high-injection pressure diffused to the outside perimeter of the sample, making the fluid pressure at localized locations along the sample/membrane interface increase close to or larger than the confining pressure level. As a result, the seal provided by the membrane to the sample was lost. In some situations, the sample collapsed, losing its integrity and making it unusable for further visual and CT observations.

One consequence of the previously described complexities has a high failure rate in the current laboratory test program. For example, nearly 30 samples were attempted but only 13 samples could be used for analysis. Therefore, the laboratory test conditions in the test result analysis appeared not to be systematically designed. For example, when we compare two results of different tests, we found more than one different test conditions between them. Efforts were also undertaken to test if the conditioning phase could help samples with a similar initial stress condition to sample B9 in Figure 11 to form the microcrack fracture pattern. Unfortunately, we failed to yield conclusive results.
The complexities typically happened on samples that exhibited complex fracture patterns. This can be observed in Figure 6 on sample B7 and in Figure 8 on sample B, in which the sample was no longer a good cylindrical shape on the CT scans. On the contrary, samples that exhibited discrete fracture patterns tended to maintain their cylindrical shape well (as shown in Figure 5 on sample B9 and in Figure 8 on sample A).

Therefore, we believe that the test results are valid at least on the distinction of microcrack fracture patterns vs. discrete fracture patterns. It led the high-injection pressure inside the sample to leak along multiple paths toward multiple points along the membrane/sample interface, compromising the seal.

Fracture complexity is a success index in hydraulic fracturing stimulations. Cipolla et al. [13] devised a term called fracture complexity index, which is equal to the width-tolength ratio of the fracture created during the stimulation and imaged by the microseismic monitoring. A simpler fracture geometry means that it appears to be narrow, single or multiple planar, not easily branched or deviated, i.e., closer to the theoretical vision about a fracture as a planar discrete interface feature.

Fracture complexity is influenced by many geological factors, including in situ stress anisotropy, rock mechanical property anisotropy, and existence, and mechanical and spatial properties of natural fractures present in the target formation. The stress anisotropy refers to the difference between the 
maximum and minimum in situ principal stresses. Influence of the in situ stress anisotropy on the fracture geometry is often discussed in the presence of natural fractures.

In situ stress condition evolves during a hydraulic fracturing stimulation job. So is the stress anisotropy. Soliman et al. [14] utilized these characteristics in devising their concept of "Texas Two Step Method" to promote complex hydraulic fracturing behavior. Therein, the stress anisotropy decreases between two earlier-created fractures and thus a higher probability for complex fractures to occur in the region between. Again, it is believed that a smaller stress anisotropy favors for more complex fracturing behavior to occur.

Natural fractures are one type of inherent defects in rock masses. The other types include microopen spaces (pores, vugs) and grain boundaries. Interestingly, Li et al. [15] presented numerical simulations about impact of stress anisotropy in ultralow permeability sandstone reservoirs which have heterogeneous gravel conglomerates dispersed in otherwise finely grained sandstone, which is collectively called tight glutenites. It shows that a larger stress anisotropy promotes hydraulic fractures penetrating through the gavels to form a simpler fracture geometry [15]. No microcracks or natural fractures are present in the simulations. Therefore, it is believed that results reported on impact of in situ stress anisotropy in naturally fractured reservoirs should be equally relevant to rock formations that are not obviously naturally fractured.

The present paper suggests that shear-induced dilation can cause complex fracturing behavior. Proper management of the high-pressure injection conditions can overcome the impact of a high in situ stress anisotropy, which otherwise favors a simpler fracture geometry, to cause the desired fracture complexity. It is hoped that results presented in this paper provide a new paradigm about reservoir stimulation. Stimulation is to alter the rock structure, creating new contact areas for the original oil/gas in place gathering and then flowing to the production well and for the stimulating materials/energy to distribute inside the reservoir and contact hydrocarbon. Besides its tensile mode, rock fracturing can take place in a shear mode where the two fracture interfaces are still in contact-although they can be offset by a certain distance. The shear failure causes dilation, also creating new porosities and hydraulic pathways (i.e., the shear failure can contribute to the reservoir stimulation, too). The present paper provides laboratory evidence supporting that the shear failure mode can be used to create a microcrack-dominated fracture pattern, not a discrete tensile fracture pattern. Hydraulic injection condition can be proactively managed to allow the shear failure mode to occur.

\section{Data Availability}

We have the permission of CNOOC Research Institute and BitCan G\&E Inc. for allowing the publication of this paper.

\section{Conflicts of Interest}

We declare that we do not have any commercial or associative interest that represents a conflict of interest in connection with the work submitted.

\section{Acknowledgments}

We would like to thank CNOOC Research Institute and BitCan G\&E Inc. for allowing the publication of this paper. Various colleagues at CNOOC Research Institute and BitCan carried out the laboratory test program, whose contributions are duly acknowledged.

\section{References}

[1] Y. G. Yuan, B. H. Yang, and B. Xu, "Fracturing in the oil-sands reservoirs," in CSUG/SPE 149308 presented at 2011 CSUG/SPE Canadian Unconventional Resources Conference, Calgary, Canada, 2011.

[2] Y. G. Yuan, B. Xu, and B. H. Yang, "Geomechanics for the thermal stimulation of heavy oil reservoirs," in Canadian experience SPE 150293 presented at the SPE Heavy Oil Conference and Exhibition, Kuwait City, Kuwait, 2011.

[3] Y. G. Yuan, "Hydraulic dilation stimulation to improve steam injectivity and conformance in thermal heavy oil production," in SPE 193681 presented at the SPE Heavy Oil Conference and Exhibition, Kuwait City, Kuwait, 2018.

[4] Y. G. Yuan, B. Xu, and B. H. Yang, "Application of geomechanics in heavy oil production - advanced Canadian experience," in Presented at 70 Simposio Internacional de Geomecanica 2017: "Sustainable Heavy Oil Exploitation, Innovation and Geomechanical Contributions, Medellin, Antioquia, Colombia, 2017.

[5] Cenovus FCCL Ltd, "Christina Lake thermal project. Enhanced start-up application for well pads B03, B04, B05 and B07," Alberta Energy Regulator (AER) Application No. 1666419, 2010.

[6] Cenovus FCCL Ltd, "Cenovus Christina Lake in-situ oil sands scheme (8591) 2010-2011 update," Alberta Energy Regulator (AER) In-situ Performance Presentations, Annual, 2011.

[7] Cenovus FCCL Ltd, "Cenovus Christina Lake in-situ oil sands scheme (8591) 2011-2012 update," Alberta Energy Regulator (AER) In-situ Performance Presentations, Annual, 2012.

[8] Cenovus FCCL Ltd, "Cenovus Christina Lake in-situ oil sands scheme (8591) 2012-2013 update," Alberta Energy Regulator (AER) In-situ Performance Presentations, Annual, 2013.

[9] Y. G. Yuan, Method for Fast and Uniform SAGD Start-up Enhancement, BitCan patent application. Canadian patent no. granted: 2,817,612, 2013.

[10] J. Zhang, Y. Fan, B. Xu, B. Yang, Y. Yuan, and Y. Yu, "Steam circulation strategies for SAGD wells after geomechanical dilation start-up," in SPE 180705-MS presented at the SPE Canada Heavy Oil Technical Conference held in Calgary, Alberta, Canada, 2016.

[11] Y. Fan, X. Sun, X. Mai, B. Xu, M. Dong, and Y. Yuan, "In-situ catalytic aquathermolysis combined with geomechanical dilation to enhance thermal heavy-oil production," in $S P E$ 184981-MS presented at the SPE Canada Heavy Oil Technical Conference, Calgary, Alberta, Canada, 2017.

[12] Y.P. Vaid and D. Negussey, "Preparation of reconstituted sand specimens," in Advanced Triaxial Testing of Soil and Rock, R. T. Donaghe, R. C. Chaney, and M. L. Silver, Eds., pp. 405417, American Society for Testing and Materials (ASTM), Philadelphia, USA, 1988.

[13] C. L. Cipolla, M. J. Warpinski, M. J. Mayerhoff, and E. P. Lolon, "The relationship between fracture complexity, 
reservoir properties, and fracture treatment design," in Paper SPE 115769 Presented at 2008 SPE Annual Technical Conference, Denver, CO, 2008.

[14] M. Y. Soliman, L. East, and J. Augustine, "Fracturing design aimed at enhancing fracture complexity," in SPE 130043 Presented at SPE EUROPEC/ EAGE Annual Conference and Exhibition, Barcelona, Spain, 2010.

[15] Z. Li, L. Li, Z. Zhang et al., "The fracturing behavior of tight glutenites subjected to hydraulic pressure," Processes, vol. 6, no. 7, p. 96,2018 